\title{
Reflexiones críticas de la sostenibilidad como construcción políticamente correcta del desarrollo
}

\author{
Víctor Rodríguez Martínez \\ Universidad Autónoma del Estado de México, México \\ vic_hugo8@hotmail.com \\ Rafael Sánchez Barreto \\ Universidad Autónoma del Estado de México, México \\ rfsanchezb@uaemex.mx
}

\begin{abstract}
RESUMEN
El desarrollo sostenible y los Objetivos de Desarrollo Sostenible, ODS 2030, no plantean una salida real de la actual crisis civilizatoria, de la que cada vez se habla más en espacios académicos, sociales y políticos. Por tanto, el discurso tan difundido por organismos internacionales, gobiernos, empresas transnacionales y algunos miembros de la sociedad civil, del desarrollo sostenible, únicamente refleja una postura denominada "políticamente correcta», en tanto que promueve una serie de valores y postulados heredados de la razón modernizadora, encaminados a anular la conciencia crítica de la población sobre los verdaderos causantes de dicha crisis, que son el sistema de capitalismo salvaje con sus consecuentes derivados del consumo exacerbado y la explotación intensiva de los bienes naturales. En tal sentido, más allá del desarrollo sostenible y sus objetivos 2030, está la propuesta de la sustentabilidad, como una alternativa real y emancipadora encaminada a configurar una nueva realidad global sobre la base de relaciones armónicas y saludables entre los seres humanos y de estos con la naturaleza, percibiéndose como parte integral de ella. Por ello, resulta fundamental develar la construcción teórica y conceptual de los vocablos «desarrollo» y «desarrollo sostenible», a través de su revisión histórica, epistemológica y discursiva.
\end{abstract}

Palabras clave: Sustentabilidad, modernidad, desarrollo sostenible

\section{Critical reflections on sustainability as an appropriate political framework of development}

\begin{abstract}
The Sustainable Development and the Sustainable Development Goals, 2030 SDG, do not arise a real way out of the present civilizing crisis, the one that is taking place in more and more academic, social and politics scenarios. Therefore, the sustainable development speech so spread by the international organizations, government, transnational enterprises and some members from the civil society, only reflects a point of view called «appropriate politically». This is the one promoting a variety of values and postulates inherit from a modern way of thinking aimed at overriding critical conscience of the people in relation to the real causes of that crisis. Among these causes, we can mention the system of the Wild Capitalism and its consequences that come from the exacerbated consumerism and the intensive exploitation of the natural resources. To that effect, beyond the sustainable development and its goals 2030, this sustainable proposal, as a real and independent alternative, aimed at configuring a new global reality on base of healthy and harmonic relations between human beings and, human beings and nature as recognizing themselves as part of it. Because of it, it is very important to unveil the theoretical and conceptual construction of
\end{abstract}


the words «development» and «sustainable development» this through the historical, epistemological and discursive review.

KeYwords: Sustainable, modernity, sustainable development

\section{Introducción}

El presente ensayo está encaminado a realizar una reflexión crítica del desarrollo sostenible como construcción e instrumento políticamente correcto que sirve para evadir los problemas fundamentales generados por el modelo económico global imperante y sus extensiones pragmáticas: el extractivismo y el consumismo. Esta reflexión se hace sobre la base de la revisión histórica y conceptual de ambos vocablos, desarrollo y sostenibilidad, a la luz de la razón modernizadora.

Se revisa también la sustentabilidad como condición contraria a lo que refiere el discurso políticamente correcto del desarrollo sostenible y cómo dentro del paradigma de la sustentabilidad se promueven caminos distintos de relación entre el ser humano y su ambiente, así como entre los propios seres humanos.

Se hace una primera aproximación conceptual basada en la revisión epistemológica de lo que implica el desarrollo sostenible y la sustentabilidad como posiciones contrapuestas, desde perspectivas emancipadoras como las denominadas epistemologías del sur.

\section{Inicio}

El presente ensayo dará inicio contrariamente a lo que los convencionalismos de la escritura académica establecen, es decir, iniciará con las conclusiones, por tanto:

Premisa Uno. La Sustentabilidad desde el pensamiento contrahegemónico, decolonial y emancipador, emanado principalmente desde ideologías o posturas críticas del sur -entendiendo este «sur», como construcción epistemológica distinta y contrapuesta a los discursos homogeneizantes, totalizadores, imperialistas, globalizadores y unilaterales, que tienen como base teórica e ideológica la razón objetivizadora de la llamada Modernidad, y no como una postura meramente geográfica- se constituye hoy en día como el mayor paradigma alternativo a lo que en la actualidad se ha extendido como discurso políticamente correcto de organismos e instituciones internacionales, agencias globales de desarrollo, gobiernos autodenominados de primer mundo, consorcios multinacionales, bancos multilaterales de desarrollo, empresas transnacionales y algunos gobiernos locales traidores del interés superior de su pueblo, que es el «Desarrollo Sostenible». 
Premisa Dos: El discurso del desarrollo sostenible es la herencia cultural, política e ideológica de la denominada razón modernizadora, que inicia como etapa histórica de occidente, aproximadamente entre los siglos XV y XvI y donde se presenta una ruptura gradual, pero evidente con un estado premoderno o medieval que privilegiaba, entre otras cuestiones, el pensamiento teocéntrico como descriptor primordial de la realidad, la no propiedad privada y la producción de base agrícola, mayoritariamente para el autoconsumo, una postura de simbiosis o unificación entre el hombre y su entorno biofísico, etcétera. En tal sentido, la Modernidad rompe con tales cuestiones convirtiéndose en una posición, incluso antagónica, a saber, el pensamiento antropocéntrico, la propiedad privada como elemento fundamental de la libertad individual, y destacadamente, la creación de la falsa — a nuestro parecer — dicotomía hombre-naturaleza. Luego entonces, el desarrollo sostenible tiene histórica y conceptualmente como hermanos mayores (en tanto su aparición cronológica aproximada), a la globalización, el primer mundo, la periferia o países satélites, el tercermundismo, el industrialismo, el norte-sur, el desarrollo (especialmente el inaugurado por el expresidente estadounidense H. Truman), el pensamiento occidental, el orden y el progreso, el modernismo, lo objetivo y la civilización versus lo salvaje. Asimismo, el desarrollo sostenible tiene algunos medios hermanos conceptuales, un tanto rebeldes que aparecieron en distintos momentos y que no prosiguieron totalmente los cánones heredados de la modernidad, tomaron por sorpresa en algunos momentos a sus impulsores y en ciertos puntos, hasta se mimetizaron con pueblos o sociedades de libre pensamiento. Como los derechos humanos, la democracia y la ciudadanía.

Premisa Tres. El desarrollo sostenible, tal como lo hicieron sus antepasados conceptuales, busca implantar una forma de pensamiento (colonial) en donde los pobladores de los países no hegemónicos se sientan culpables por algo que no han hecho, al menos directamente ni en la escala de sus contrapartes de países hegemónicos — la explotación exacerbada de los bienes naturales, por ejemplo—, y donde además, se alude a una supuesta preocupación por el medio ambiente, cuando la verdadera preocupación es proteger las ganancias de una ínfima minoría que controla la aplastante mayoría del capital financiero mundial. Bajo esta lógica se les transfiere la responsabilidad a los países llamados «en vías de desarrollo» por no contar con la tecnología suficiente para aminorar los impactos ambientales derivado de las actividades productivas, y además por tener un alto número de personas viviendo en condiciones de pobreza que no tienen otra opción, más que usufructuar intensamente el medio en el que viven, que dicho sea de paso, nunca se podrá comparar con la actuación de una industria transnacional; desviando así la atención sobre las corporaciones transnacionales que realizan una extracción salvaje de hidrocarburos, minerales u otros, obligando a los países en vías de desarrollo a acatar planes y programas de sostenibilidad, a comprar tecnología para aminorar los impactos ambientales, a mantener zonas territoriales vírgenes que ayuden a amortiguar los 
efectos de la industria en las sociedades desarrolladas, a establecer agencias de vigilancia del ambiente con cargo, por supuesto, al erario público de esas naciones a cambio de un reconocimiento o certificación otorgado por los más grandes contaminantes, claro; prolongando así, el ciclo que pareciera eterno de dependencia económica, tecnológica y política hacia los grandes centros del capital, los países desarrollados. Y desde luego con todo esto, generar una nueva moda que se sostendrá de la innovadora actividad empresarial constituida por consumir "productos verdes», es decir, una «economía verde».

Premisa Cuatro. La sustentabilidad, como paradigma e idea ética emancipadora, respetuosa de las realidades contextuales, holística e integradora de conocimiento, no sólo científico, sino tradicional, artístico, originario o simplemente distinto, multidimensional, lo cual quiere decir que incorpora más allá de las tres aristas tradicionales, la ambiental, la económica y la social, sino otras dimensiones como la espiritual, la valorativa, ética y filosófica, y que es además sistémica y compleja, no es un sinónimo o extensión de la sostenibilidad o desarrollo sostenible. Más aún, es como se señaló en la premisa uno, un constructo alternativo, diferente y en muchos puntos, contrapuesto, que busca redireccionar las capacidades comunales hacia una nueva forma de relacionamiento social y con la naturaleza que detenga la crisis civilizatoria y que siembre una realidad próspera y alentadora para todos los pueblos del mundo.

\section{Aproximaciones conceptuales e históricas del desarrollo}

El desarrollo es sin duda uno de los términos más utilizados por autoridades gubernamentales y representantes populares. Se alude al desarrollo como un estadio aspiracional al que toda colectividad quisiera llegar, y se vuelve ambiguo, cuando su uso no define contextos ni situaciones específicas, es decir, cuando se señala por ejemplo que el desarrollo es aquella cuestión que mejora las condiciones de vida de una población, por tanto, no es algo que se pueda o deba cumplir necesariamente, puesto que tales condiciones de vida de un pueblo o localidad son tan heterogéneas, que la aplicación del término puede quedarse sin ningún problema en el terreno de lo retórico o abstracto. Es más, es casi obligado que en un discurso público se utilice, al menos una vez, esta referencia.

$\mathrm{Al}$ no establecer un parámetro concreto y definido para generar, ampliar, fortalecer o modificar las mejores condiciones de vida de una sociedad, el interlocutor que basa su discurso en dicha propuesta ambigua, no tendrá ningún problema a la hora de la rendición de cuentas, ya que, hasta la colocación de una banca en un jardín público puede referirse como una mejora de las condiciones de las personas que utilizan ese espacio. 
Sin embargo, el referente conceptual e histórico de este término, remite a una mayor complejidad en su construcción, definición y aplicación, que la ligereza con la que es usado comúnmente.

Así, tenemos que un primer acercamiento a aquello que podemos develar sobre lo que es e implica el desarrollo, nos lo decodifica Arturo Escobar (2007), pues señala que este debe ser visto como un régimen de representación, como una «invención» que resultó de la historia de la posguerra y que desde sus inicios, moldeó ineluctablemente toda posible concepción de la realidad y la acción social de los países que desde entonces se conocen como subdesarrollados. Entonces desciframos, con las palabras de Escobar, que aquellos que inventaron el término en su concepción más reciente, es decir la posguerra, definieron al mismo tiempo que existiría una única vía de concebir la realidad o de leer dicha realidad: el «desarrollismo». Por tanto, debió construirse, además, todo un corpus ideológico institucional que orientará el pensamiento e imaginación de todo el mundo a suponer que no existía otro camino para el bienestar o prosperidad de los pueblos, más que ese discurso del desarrollo.

Como ya lo han abordado distintos autores, Escobar (2007), Esteva (1996), Mota y Sandoval (2016), la versión institucionalizada del desarrollo, como uno de los objetivos primordiales de las organizaciones gubernamentales, queda inaugurada formalmente con el discurso de toma de posesión del presidente estadounidense Harry Truman en 1949. Cuando este introduce el término de «subdesarrollo» queda amalgamada la nueva doctrina capitalista con la que deben conducirse todos los países a partir de ese momento, el desarrollismo, que tendrá como base la industrialización, pero sobre todo, la base de que para ser mejores países o para superar problemas como la pobreza, estos deberán hacer todo lo necesario para moldearse a imagen y semejanza de los Estados Unidos.

Como alude Gustavo Esteva (1996), ese día en el que Truman dicta su discurso, se incorporó de un plumazo a dos mil millones de seres humanos en el subdesarrollo, al tiempo que el término fue aceptado automáticamente en el concierto internacional en el momento de su acuñación política. En perfecta concordancia con la lógica modernizadora de estandarizar y suprimir elementos tradicionales, el día en que se pronuncia tal discurso, Estados Unidos emprende una campaña mundial para transferir sus bases ideológicas a todos los pueblos, además de su prosperidad económica y desarrollo tecnológico. Aunque ciertamente, lo que se transfirió en mayor medida fueron los riesgos, los problemas y malos resultados, de políticas basadas en el crecimiento económico sostenido por la industrialización y la sobre explotación de los bienes naturales; la prosperidad económica y el desarrollo tecnológico han quedado en el terreno de lo inalcanzable, como una liebre tras una zanahoria amarrada a su cuerpo y colgando frente a su cara, la cual siempre se percibe muy cercana, pero nunca logra atraparse.

De esta manera se delineó la forma tan ambigua en la que hoy se utiliza el concepto de desarrollo, o sea, no importa qué signifique propiamente «desarrollo» siempre 
y cuando nos haga escapar de esa condición indigna y marginal de "subdesarrollo». Entendemos pues, basándonos en Escobar y Esteva que la construcción del subdesarrollo es una representación arquetípica de aquello que es contrario a la forma de vida de los grandes centros de poder, o propiamente de los países desarrollados encabezados por Estados Unidos, donde se configura una ilusión que se basa en que cada país que no siga los dictados de las estrategias o políticas desarrolladoras, es decir que no elimine o minimice sus instituciones tradicionales, sus rasgos culturales, sus elementos históricos que les dotan de identidad propia, estarán condenados a no salir de la condición de subdesarrollo; y por lo tanto, no pertenecerán al molde de progreso y bienestar del que disfrutan los países hegemónicos, marcando una nueva etapa, si bien dejando atrás el colonialismo europeo, si bajo la misma línea de dominación y explotación, pero ahora desde Estados Unidos principalmente, y con la implantación de discursos ideológicos que dictan el rumbo desde el occidentalismo hegemónico.

Pero la institucionalización del concepto de desarrollo o el respaldo político de los grandes centros de poder a ese adjetivo o epíteto que transfiguró las realidades propias de muchos países, no quedó inamovible o totalmente construido en ese discurso de Truman o en sus pasadas conceptualizaciones, se ha ido modificando o regenerando a pesar de las críticas y de los lamentables resultados, tal como lo mencionan Mota y Sandoval (2016), que en cada fase que se ha vivido bajo tal modelo, se puede afirmar que siempre ha prevalecido el interés capitalista, soslayando las necesidades sociales de una gran mayoría de la población; asimismo los autores retoman el pensamiento de Aníbal Quijano donde establece que históricamente la construcción social del desarrollo ha tenido una base común: la acumulación capitalista por medio de la colonización ${ }^{1}$, expresada en distintas formas de dominación, explotación y despojo hacia las naciones consideradas pobres y atrasadas. Y subrayan -Mota y Sandoval- que las condiciones actuales de las mayorías, principalmente en los países adjetivados como subdesarrollados, demuestran que, a pesar de todas las reformulaciones el desarrollo convencional con dimensiones sustancialmente económicas ha dejado a su paso un enorme deterioro social que se manifiesta en la crisis civilizatoria que vivimos actualmente.

1 A propósito de las referencias hechas en este documento a los procesos y discursos coloniales, o para el caso el nuevo colonialismo como amalgama del discurso políticamente correcto del desarrollo sostenible, cabe rescatar lo que Santiago Castro-Gómez, específicamente en una entrevista que le realizaran Hernández y Rodríguez (2012), señala que el colonialismo es un fenómeno de orden molar, que atañe el modo en que los países de América Latina se inscriben asimétricamente en un sistema global de dominación que les excluye y les condena a la dependencia económica. Mientras que la colonialidad es un fenómeno de orden molecular, que atańe el modo en que los sujetos valoran sus relaciones con los demás, con el conocimiento y consigo mismos. Por tales razones -remarca CastroGómez- la colonialidad, en tanto del poder, del saber y del ser, representa un modo de valoración que no deriva simplemente de una la lógica económica y geopolítica generada por el colonialismo, aunque al inicio ambos fenómenos estuvieran íntimamente ligados, sino que la colonialidad se desarrolló históricamente de manera independiente del colonialismo después de los movimientos de independencia en el caso de los países Latinoamericanos (pp.190-191). 
El soporte práctico para mantener durante tantos ańos el discurso totalizador del desarrollo, está centrado en la existencia de millones de seres humanos en condiciones de pobreza, por tanto la pobreza constituye el referente justificador para que los gobiernos emprendan planeaciones nacionales encaminadas a la desaparición de dicha condición, con base en la obtención de tecnología de punta para poder producir más y con ello alcanzar la paz y prosperidad, puesto que en palabras del propio Truman: «la clave para producir más es la aplicación mayor y más vigorosa del conocimiento técnico y científico moderno.»

El proyecto del desarrollo seńala Escobar (2007), era crear las condiciones necesarias para reproducir en todo el mundo los rasgos característicos de las sociedades avanzadas de la época: altos niveles de industrialización y urbanización, tecnificación de la agricultura, rápido crecimiento de la producción material y los niveles de vida, y adopción generalizada de la educación y los valores culturales modernos. Por tanto, el capital, la ciencia y la tecnología eran los principales componentes que harían esa revolución masiva posible. Cuestión que como sabemos, nunca terminó por realizarse. Así que, con lo dicho anteriormente, la definición concreta de desarrollo hoy en día debería ser: «esquema imaginario en el cual se busca reproducir los estándares y valores de una sociedad (hegemónica), sin tomar en cuenta las circunstancias propias del lugar donde se intenta implantar, con la falsa idea de que se generarán mejores condiciones de vida, sean cuales fueren estas».

Para el propio Escobar es clara la forma de entender las condiciones que propiciaron que países hicieran suya una propuesta dominante que los orillaba a sacrificar sus propios puntos de vista, de tal suerte señala que: «Ver el desarrollo como discurso producido históricamente implica examinar las razones que tuvieron tantos países para comenzar a considerarse subdesarrollados a comienzos de la segunda posguerra, cómo "desarrollarse» se convirtió para ellos en problema fundamental y cómo, por último, se embarcaron en la tarea de «des-subdesarrollarse» sometiendo sus sociedades a intervenciones cada vez más sistemáticas, detalladas y extensas» (2007, p. 23). Con estas aseveraciones de Escobar se puede fácilmente deducir porqué la idea del desarrollo como estrategia para afrontar los problemas del subdesarrollo, creada inicialmente en Estado Unidos y Europa occidental, se convirtió rápidamente en una fuerza tan poderosa en las naciones adjetivadas como del Tercer Mundo.

Como corolario de este apartado, es preciso señalar que en más de cincuenta años de construido el discurso del desarrollo y subdesarrollo y trasplantado a los diferentes puntos del planeta, este no ha reducido, ni la brecha entre ricos y pobres, ni la cantidad de pobres. La paz y prosperidad pugnados con base en el conocimiento científico y tecnológico, en la industrialización, en el crecimiento económico acelerado, en la democracia occidental, aún no han llegado. Con cierto tono sarcástico podríamos decir, 
que quizás no se ha logrado por el mal entendimiento de las directrices por parte de los países subdesarrollados.

\section{Aproximaciones conceptuales e históricas de la sostenibilidad}

Durante la década de los ochenta del siglo pasado, se presentó en la Organización de las Naciones Unidas (ONU), un informe por parte de la Comisión Mundial para el Medio Ambiente y el Desarrollo (CMMAD), sobre el medio ambiente y su problemática hasta el año 2000. Dicho informe llamado «Nuestro futuro Común» se popularizó con el apelativo de Informe Brundtland, debido a la encargada de dicha comisión, Gro Harlem Brundtland, ex Primer Ministra de Noruega. Tal documento adjetivó políticamente lo que debía ser un tipo de desarrollo para el mundo, es decir, ya no solo debían los países de desarrollarse, sino, además, tal desarrollo debería contar con ciertas características; este se denominó: desarrollo duradero o sostenible. En propias palabras del texto se establece como: «...hacer que el desarrollo sea sostenible, duradero, o sea, asegurar que satisfaga las necesidades del presente sin comprometer la capacidad de las futuras generaciones para satisfacer las propias...»(CMMAD, 1987, p. 23).

Este señalamiento que se hace en términos de duradero o sostenible por parte de la Comisión, es el referente conceptual más extendido y popularizado sobre «desarrollo sostenible». Y resulta trascendental que se subraye el marco en el cual se presenta, es decir, el seno de la organización internacional con mayor legitimidad en el mundo, la ONU, esto le confiere una significación distintiva al uso que vendrá después de la palabra.

Conjugando criterios e intentando reflexionar críticamente, pero dejando volar la imaginación, los contextos en que nacen nuestros términos son distintos, pero tienen un común denominador. Primero, el expresidente estadounidense Truman, da un giro al concepto de desarrollo en el marco de su toma de protesta y más relevante aún, en el marco de la posguerra, donde se habían alzado con la victoria los países aliados, en los cuales Estados Unidos se erigió como uno de los salvadores, y en ese momento se convertía en el principal aliado de Europa financiando parte de la reconstrucción. Luego entonces, Estados Unidos contaba con una alta aceptación, credibilidad y legitimidad por parte de sus aliados occidentales y en el resto del mundo. Segundo, en la década de los ochenta después de una serie de guerras, invasiones e intromisiones en distintos países, los estadounidenses ya no gozaban de la fama y popularidad de los años de posguerra, más bien, se habían erigido ahora como invasores y promotores de conflictos bélicos, es así que el marco más idóneo para un planteamiento "políticamente correcto» para adjetivar un tipo de desarrollo que generara respaldo y aprobación en la comunidad internacional sin ningún tipo de presión visible, no era precisamente un 
representante de los Estados Unidos, pero sí un organismo donde contaban o cuentan con amplia injerencia, la ONU.

No se pretende decir con ello que existió una gran conspiración para implantar maléficamente una forma de desarrollo que buscara atemperar los estragos causados en el medio ambiente, pero que al mismo tiempo beneficiara únicamente a ciertos grupos o países. La cuestión es que el común denominador de ambos conceptos se encuentra en que reflejan sino explícita, sí implícitamente, una transferencia de responsabilidades sobre las condiciones sociales, políticas, económicas y ambientales imperantes en el mundo, a los países más vulnerables en términos económicos, políticos y sociales, es decir, los que fueron llamados subdesarrollados; siendo que estos siempre han sido los menos favorecidos con los modelos de desarrollo implantados en el mundo. Así se observa que está implícita en estas construcciones ideológico-políticas del desarrollo y desarrollo sostenible, que los países tercermundistas, al encasillarlos como subdesarrollados, eran culpables por no saber cómo hacer que el modelo capitalista imperante en el mundo, promoviera la salida de los pobres hacia mejores condiciones, y así tener una menor desigualdad al interior, de igual modo, son culpables del deterioro ambiental, por no contar con la tecnología suficiente para ayudar a reducir dicho deterioro.

En otras palabras, tanto el desarrollo como el desarrollo sostenible postulan una serie de planes, acciones, directrices y adjetivos, con los que se debe alinear todo el mundo, pero en ningún caso se contempla un cambio radical en el modelo que ha, precisamente generado las condiciones vulnerables del planeta, tanto en términos ambientales, como sociales, es decir, el capitalismo. Según estos conceptos, la ruta para superar la pobreza o cuidar los bienes naturales, es incorporar estrategias de atemperamiento, pero no de transformación profunda, el sistema capitalista con su modelo consumista queda intacto. Por ello, sería complicado señalar que tanto Harry Truman como el informe Brundtland, no actuaban preocupados por la situación mundial, pero ciertamente no se percibe un intento serio y profundo por reconfigurar las relaciones asimétricas imperantes, y más aún, abismalmente desiguales entre los países desarrollados y los que estaban o están todavía en vías de desarrollo.

En el análisis que realizan Mota y Sandoval (2016) sobre la definición de desarrollo sostenible derivada del informe Brundtland, afirman que en esencia lo que plantea dicho informe es obtener un crecimiento económico a partir de la implementación de políticas de sostenibilidad, además de la expansión de la base de recursos ambientales, lo que creían podía lograrse con acciones encaminadas a promover un buen manejo de los recursos naturales. Sin embargo, es clara la intención de continuar privilegiando el crecimiento económico por encima de la preservación ambiental, relegando totalmente al ambiente a un papel secundario.

En la misma tesitura, Bermejo (2014) señala que existen manipulaciones dentro del término de desarrollo sostenible, pues a pesar de que las instituciones de gobier- 
no suelen comenzar sus informes aceptando el concepto establecido por el informe Brundtland, acaban definiendo conceptos que son contradictorios con él y entre sí, lo que crea una cacofonía barroca de términos que carecen de precisión, pero detrás de ella aparece un propósito central: la defensa del crecimiento ilimitado, aunque sostenible, cuyo adjetivo se sustituye, cada vez más por el de verde que es más fácil de manipular. Así que la interpretación más común del concepto de desarrollo sostenible es la de una estrategia de crecimiento económico sostenido, pero no el apoyo al florecimiento y mantenimiento de una vida natural y social infinitamente diversa.

Este crecimiento que durante mucho tiempo se pensó como ilimitado, está en clara concordancia con la llamada modernidad, pues como se ha manifestado, dentro de tal escenario se plantea una lógica de objetivizar a los bienes naturales como recursos, es decir, percibirlos casi exclusivamente como valores de uso para las relaciones económicas de los seres humanos, en tanto contribuyan a la generación de riqueza material y por tanto al crecimiento. Y si bien los postulados del desarrollo sostenible, así como de las diversas convenciones, reuniones u organismos multilaterales donde se expone y respalda dicho término, reconocen, asumen y hasta evidencian las complicaciones en el entorno biofísico, no se deja de buscar el crecimiento con base en la explotación exacerbada de los bienes naturales, objetivizados como recursos. Se insiste, con el advenimiento de lo sostenible se percibe una preocupación por el deterioro de la base ambiental, pero ello no significa que se haya planteado una propuesta profunda e integral que construya una alternativa que detenga dicha condición de insostenibilidad.

Es evidente pues, que la razón modernizadora con su lógica totalizadora, estandarizante e invisibilizadora de las diferencias culturales, necesitó re-significar a los bienes naturales como cosas-instrumentos de carácter utilitario para el impulso del modelo capitalista que ensalza la ganancia individual y promueve el consumo infinito de mercancías como única filosofía de vida, en donde la posesión cada vez mayor de productos y su respectiva actualización sin fin, es considerada el nuevo camino al bienestar, al desarrollo o a la felicidad.

Por ello Vandana Shiva (1996) señala la resignificación del propio término «recurso», el cual implicaba una regeneración de los elementos que la tierra le proporcionaba al hombre, hasta que con la irrupción del industrialismo y el colonialismo se produjo un quiebre conceptual donde los «recursos naturales» se transformaron en aquellas partes de la naturaleza, que eran requeridas como insumos para la producción industrial y el comercio colonial. Refiere la misma autora, que un autor del siglo XIX, llamado J. Yeates en su obra Historia Natural del Comercio, ofreció la primera definición de «recursos naturales», pero ya desposeída totalmente del carácter de dignidad o de simbiosis con el ser humano, más bien, estaba ya cargada de objetivizaciones materiales sin ninguna carga simbólica cualitativa: "Al hablar de los recursos naturales de un país cualquiera, nos referimos al mineral en la mina, la piedra en la cantera, la madera en el bosque 
(etc.)». Enfatiza Shiva que, en esta mirada la naturaleza ha sido claramente despojada de su poder generador; se ha convertido en un depósito de materias primas que esperan su transformación en insumos para la producción de mercancías. Los recursos son ahora meramente «cualquier material o condición existente en la naturaleza que puede ser capaz de explotación económica».

Los elementos naturales, provistos prolíficamente sin la mediación del hombre, fueron [re]significados por la ética de la razón moderna. Este proceso de resignificación derivó en la concepción actual desvalorizada que se tiene de estos, ahora «recursos naturales» y materias primas parece que deben estar al alcance del ser humano por cualquier medio para satisfacer sus necesidades. Pero también, cierto es que en las últimas décadas ha cobrado una especial importancia el interés por el cuidado de estos recursos, más aún, por su revalorización y reposición como elementos que permiten la regeneración de la vida misma, y no sólo como una materia prima que espera pacientemente a ser transformada por la mano del hombre para solo así, cobrar cierta relevancia. El destino de la naturaleza tiene su propia lógica conductual, y no sólo está anclada al provecho o comodidad del ser humano.

Retomando de nueva cuenta lo referente a los antecedentes del propio concepto de desarrollo sostenible, y de la misma CMMAD, donde se comenzaba a considerar que se estaban presentando condiciones cada vez más adversas para el planeta y que esto promoviera mayores investigaciones al respecto, así como que fueran temas considerados por la ONU, encontramos el libro «Primavera Silenciosa» de Rachel Carson, el cual refiere las observaciones e investigaciones de esta científica en torno a los métodos aplicados en la agricultura, los productos utilizados en ella y por ende los daños ambientales que causaban. De igual manera otro antecedente fundamenta fueron los estudios patrocinados por el llamado "Club de Roma» en torno a la imposibilidad de continuar con el ritmo de crecimiento material y económico que hasta ese entonces se venía presentando en el mundo, derivado de la sobre explotación de los recursos naturales, proponiendo distintas medidas y políticas para aminorar la carga o presión al ambiente, dichas referencias se conocieron en las décadas de los sesentas y setentas, respectivamente. (Pretty, et al, 2007).

Asimismo, se encuentra también la Conferencia de Naciones Unidas sobre el Medio Ambiente celebrada en Estocolmo, Suecia, en 1972, y de la cual derivó un documento denominado: la Declaración de Estocolmo; donde se expone la situación de emergencia en torno a la relación desarrollo económico-deterioro ambiental. En el mismo tenor, otro suceso histórico relevante para la acuñación del término desarrollo sostenible como discurso políticamente correcto, es la Conferencia de Río de 1992, conocida como: la "Cumbre de la Tierra» en la cual menciona Bermejo (2014) que, al adoptar el término de desarrollo sostenible o sustentable, se le dio a este, no al concepto del informe Brundtland como tal, un respaldo político internacional que ha llegado a 
ser parte del léxico global. Igualmente señala que es un concepto que disfruta de extendida aceptación por parte de instituciones internacionales, gobiernos, empresarios y grandes sectores de la sociedad civil.

Como corolario de este apartado es menester señalar que diversas instituciones confían en los avances científicos y tecnológicos como las posibles soluciones para aminorar los daños ambientales producidos por el ritmo de crecimiento económico, por la sobre explotación de los recursos naturales, por la cantidad de residuos producidos, etcétera, y de esta manera encontrar precisamente un desarrollo más duradero o sostenible, pero el problema que no se considera es que a la par que la tecnología avanza para prevenir o aminorar la carga ambiental, también avanza la misma tecnología y conocimiento para generar en la población mayores necesidades imaginadas o derivadas de los propios desarrollos tecnológicos, y se acentúa el esquema de consumo exacerbado, lo que se transforma en una rueda giratoria que parece cada día más imparable, donde los humanos giramos dentro de ella.

\section{Políticamente correcto}

Ciertamente en nuestros días, prácticamente nadie se atrevería a decir que una sociedad que procura alcanzar el desarrollo o que se propone satisfacer las necesidades del presente sin comprometer los recursos de las generaciones futuras, esté planteando algo incorrecto. Todo lo contrario, es uno de los discursos más populares y de prestigio en el mundo. Y si a esto le sumamos el contexto donde se plantea con mayor fuerza el modelo del desarrollo sostenible, es decir, organismos internacionales como la ONU, se presenta así el escenario perfecto para hacer del desarrollo sostenible, un planteamiento políticamente correcto.

Así pues, la alusión que se hace con el término desarrollo sostenible y que ha cautivado a gran cantidad de personas, no refleja en realidad un intento por transformar el sistema que ha provocado la crisis civilizatoria, el capitalismo. Más aún, tal sistema capitalista ha profundizado sus métodos a través del modelo neoliberal, que promueve una lógica salvaje de producción-consumo, una extracción ${ }^{2}$ rapaz de recursos y un individualismo lacerante que han logrado interiorizarse en grandes sectores de la población global, por lo que parece que es más sencillo, como lo dijera el filósofo Slavoj Zizek, «imaginar el fin del mundo, que imaginar el fin del propio sistema capitalista».

2 Para Zaremberg y Guarneros (2019), extractivismo es una actividad que se refiere al retiro de grandes cantidades de recursos naturales que son procesados, mayoritariamente para exportar, no se limita a minerales y petróleo sino también a la agricultura, silvicultura y pesca a gran escala. En otras palabras, se concibe al extractivismo como un modelo de desarrollo basado en la extracción intensiva de materias primas por medio de un proceso que presenta un bajo valor agregado. El comercio de estos recursos naturales extraídos suele cumplir un papel importante en las exportaciones nacionales. 
Pero sobre todo, el discurso del desarrollo sostenible, destacadamente el utilizado y sacralizado últimamente por los gobiernos, las empresas transnacionales y los organismos internacionales, es políticamente correcto, aunque socialmente devastador, porque estos líderes políticos o económicos nunca tocan o no lo hacen con la seriedad y profundidad debidas, los grandes contrastes y desigualdades que genera el modelo de acumulación capitalista y los cuales el desarrollo sostenible no pretende modificar sustancialmente, tan solo recetar paliativos para prolongar tal estilo de explotación, marginación y exclusión, como se evidencia con los siguientes datos abrumadores:

Imagine decirle a una familia que ha vivido en la miseria — 896 millones viven en extrema pobreza y alrededor de 2 mil 200 millones en pobreza normal - que la crisis ecológica es también su culpa y que debe hacer sacrificios para contribuir a solucionarla... la mitad de las emisiones totales de CO2 fueron responsabilidad de 10 por ciento de la población con más riqueza — 700 millones de personas_-, mientras la mitad de la población mundial —3 mil 500 millones— sólo generó 10 por ciento de las emisiones. Aún peor: según Oxfam, las emisiones de carbono del uno por ciento más rico son 30 veces mayores que las de 50 por ciento más pobre... es la coacción forzada del trabajo (tanto humano como no humano), subordinada al imperativo del beneficio a cualquier precio (la acumulación ilimitada del capital), lo que provoca la ruptura del equilibrio del ecosistema planetario. No es pues la humanidad sino una pequeñísima parte de ella la principal causante. El cambio climático no debe entonces atribuirse al mero hecho de que el planeta esté poblado por 7 mil millones, sino al reducido número de personas (uno por ciento) que controlan los medios de producción y deciden cómo se ha de usar la energía (Toledo, 2019).

Después de la cita abrumadora y clarificadora de Víctor Toledo en relación a la polarización del ingreso, y por ende a la desigualdad tan profunda, por una parte, de la riqueza material concentrada en pocas manos, y en la responsabilidad de los dańos ambientales por la otra, es preciso responder concretamente la pregunta: ‘a qué nos referimos cuando tildamos al desarrollo sostenible como «discurso políticamente correcto»? Para responder, nos apoyamos en las definiciones de ideología y discurso.

En tal sentido señala Lezama (2008), que el sistema de ideas de una sociedad, es decir la parte de la vida consciente que constituye el medio de comunicación social de la gente, emerge como la expresión abstracta y simbólica de la forma en que la sociedad funciona en todos sus ámbitos. Dentro de los distintos grupos de ideas generados, existe un conjunto delimitado por su relación con la reproducción del sistema de clases y de dominación, el cual es utilizado por una clase o grupo de clases para reproducir las relaciones sociales que hacen posible tal dominación. Con base en esto, la ideología puede ser considerada como el sistema general de ideas de una sociedad.

Así pues, la ideología equivale a una forma de sentir, pensar, experimentar y comunicar la existencia en el mundo como seres humanos. Por tanto, -reafirma Lezama- 
es el conjunto de ideas el cual expresa las diversas esferas de la subjetividad humana. Asimismo, este autor retoma a Althuser, al decir que la ideología hace posible la vida social porque constituye una especie de cemento que une a los distintos miembros de la sociedad.

En lo concerniente al discurso, este puede ser definido como: «Una combinación específica de ideas, conceptos y categorizaciones que es producida, reproducida y transformada en un conjunto particular de prácticas y a través de las cuales se les confiere significados a realidades físicas y sociales» (Hajer citado por Lezama, 2008, p. 50). Apoyado en tal definición, el propio Lezama en su análisis sobre la construcción política del medio ambiente y sus problemas, afirma que para este caso, (y el cual nosotros compararemos con la sostenibilidad), la función regulatoria de las instituciones ambientales depende de la construcción discursiva de los problemas, así pues, no es la crisis física del medio ambiente lo que provoca el cambio social, tampoco la destrucción de ciertos bienes socialmente valorados, sino la creación de imágenes, problemas identificables que permiten a gente de posiciones y perspectivas diferentes, compartir una imagen común de lo que puede ser considerado como problema.

De tal manera —ańade el autor-, el rol central que juega el discurso en el cambio político depende del supuesto de que, operando en el contexto de prácticas institucionales dadas, la interacción discursiva es un factor social constitutivo que cambia los patrones cognoscitivos y produce nuevas formas de ver y de posicionamiento en la arena política. Es asumido, por tanto, como "lucha por la hegemonía discursiva» que tiene lugar en un conjunto específico de prácticas sociales.

Por consiguiente, cuando una persona o agente social presenta una perspectiva particular y una apreciación de los problemas, está de hecho representando un orden discursivo en el cual un conjunto de precondiciones ideológicas han sido establecidas. Lo cual conlleva a que una sociedad esté mayor o menormente dispuesta a tomar acciones a favor o en contra de ciertos conceptos o ideas.

La modernidad con todos sus referentes conceptuales, teóricos, procedimentales y pragmáticos, como se señalaron en la premisa dos de las conclusiones, construyeron, implantaron y difundieron un sistema de ideas, o sea una ideología, basada en el capitalismo, en el conocimiento científico como única dirección verdadera, en la individualización por encima de la comunidad, en la separación del ser humano y la naturaleza, etcétera. Lo mismo sucedió con la idea de desarrollo de la posguerra y lo mismo sucede con el planteamiento del desarrollo sostenible y por ende, con sus objetivos conocidos como «ODS 2030».

En síntesis, consideramos lo políticamente correcto como un posicionamiento discursivo, de actores políticos, económicos o sociales con alto grado de representatividad institucional, que trata de construir en los miembros de la sociedad una serie de valoraciones subjetivas, posicionamientos políticos, afinidades cognitivas, disposiciones 
intelectuales, pero con la característica fundamental de manipular la conducta social y sesgar la opinión de las personas, intentando conservar un status quo o la hegemonía de cierto grupo o intereses. Así, al hacer cada vez más extendido el discurso políticamente correcto dentro de la colectividad se pierde en la ambigüedad su verdadero significado o sus verdaderas intenciones, como el caso del desarrollo sostenible, que a pesar de construirse con dos conceptos contrapuestos por los fines que postulan (un oxímoron le han llamado algunos), se asimila cada vez más sin la reflexión crítica de lo que implica, por ello la enorme importancia de develar su construcción teórica, histórica y epistemológica.

Como corolario de este apartado, podemos decir que teórica y conceptualmente esta falacia, como lo dijeran Mota y Sandoval (2016), del desarrollo sostenible es políticamente correcta, pero éticamente... ¡incorrecta!

\section{Otros caminos para la sustentabilidad o la sustentabilidad como otro camino}

La sustentabilidad se concibe como un paradigma alterno al desarrollo sostenible. Para tal sentido, hay que observar las propuestas transformadoras provenientes de enfoques anticoloniales y contrahegemónicos, conocer de forma más profunda y enriquecer las perspectivas que promueven visiones alejadas del control y alienamiento societal que promueve el dominio del capital.

Como señala Enrique Leff, la sustentabilidad es un quiebre, tiene que necesariamente ser un quiebre a esa razón homogeneizante, tiene que ser una apuesta renovada por una forma distinta de leer el universo. Y la entiende como: «...paradigma alternativo, en el cual los recursos ambientales se convierten en potenciales capaces de reconstruir el proceso económico dentro de una nueva racionalidad productiva, planteando un proyecto social basado en la productividad de la naturaleza, las autonomías culturales y la democracia participativa, [...] El principio de sustentabilidad emerge como una respuesta a la fractura de la razón modernizadora y como una condición para construir una nueva racionalidad productiva fundada en el potencial ecológico y en nuevos sentidos civilizatorios a partir de la diversidad cultural del género humano. Se trata de la reapropiación de la naturaleza y de la reinvención del mundo...» (1998).

Resulta imperante que los bienes naturales sean concebidos y asimilados como un constructo social distinto al que promueve la objetivación de los recursos en términos netamente económicos materiales, donde su usufructo indiscriminado fija relaciones separadas del ser humano y la naturaleza. Una relación distinta con el entorno, con los semejantes y con uno mismo, como lo menciona también Toledo y Ortiz, «...la idea de sustentabilidad, concebida como poder social, se torna sinónimo de emancipación o liberación». (2014). Esto es construir un camino alterno, distinto. 
Por ello, recalca Toledo (2015), el poder social existe y se construye y se expresa en territorios concretos, cuya escala está determinada por el nivel de organización de quienes lo ejercen, es decir, su capacidad de autogestión, autonomía, autodefensa y autosuficiencia. A propósito de las palabras de Toledo, si ese poder social existe, entonces hay muestras claras de que ya se están probando rutas distintas, que se están construyendo caminos alternos que no conducen al mismo lugar todo el tiempo, sino que trazan su propio destino.

La misma sustentabilidad llama a la recuperación de nuestra herencia cultural, de nuestro conocimiento milenario y de aquella visión simbiótica de la naturaleza y el hombre, el propio Boaventura de Sousa lo indica:

Mi versión de la utopía es, pues, doblemente relativa. Por un lado, llama la atención sobre lo que no existe en tanto que (contra) parte integrante, aunque silenciada de aquello que existe, o sea, sobre aquello que pertenece a una determinada época por el modo como está excluido de ella. Por otro lado, la utopía siempre es desigualmente utópica, dado que su forma de imaginar lo nuevo está parcialmente constituida por nuevas combinaciones y escalas de aquello que existe, y que son, en verdad, casi siempre pormenores, pequeños y oscuros, de lo que realmente existe. La utopía requiere, por consiguiente, un conocimiento abarcador y profundo de la realidad como medio para evitar que el radicalismo de la imaginación colisione con su realismo. (Santos citado por Binimelis y Roldan, 2017, p. 220).

Con lo anterior como fundamento y como corolario de este apartado, se plantea en un primer y acotado ejercicio que deberá irse profundizando, que sustentabilidad se refiere a un proceso holístico, en tanto multidimensional, sistémico y complejo que se crea y recrea circularmente con acciones constantes de menor o mayor escala en los elementos que lo conforman, cuya funcionalidad y éxito está determinada por las condiciones tangibles e intangibles de la realidad concreta en la que se formula y tiene como principio de existencia, el resplandor perenne de la vida en todas sus formas. Y subrayadamente, sustentabilidad refiere al cambio de paradigma imperante hoy día basado en el consumo ilimitado y en la sobre explotación de la naturaleza.

Por último, se destaca que el presente documento fue presentado en el VI Congreso Internacional de Sustentabilidad: «La agenda más allá de los objetivos del desarrollo sostenible», realizado en la Universidad Ricardo Palma, Lima Perú, entre el 21 y 23 de octubre de 2019. 


\section{Referencias}

Bermejo, R. (2014). Del desarrollo sostenible según Brundtland a la sostenibilidad como biomimesis. Universidad del País Vasco - Hegoa. Recuperado en http://creativecommons.org/ licenses/by-nc-nd/3.0/es/

Binimelis H. y Rolda, A. (2017). Sociedad, epistemología y metodología en Boaventura de Sousa Santos. En Convergencia Revista de Ciencias Sociales. UAEM, núm. 75, septiembrediciembre 2017, pp. 215-235

Escobar, A. (2007). La invención del tercer mundo. Construcción y deconstrucción del desarrollo. Venezuela; Fundación Editorial el perro y la rana.

Esteva, G. (1996) Desarrollo. En Diccionario del desarrollo. Una guia del conocimiento como poder. Perú, Editor Sachs Pratec.

Hernández, F. y Rodríguez, T. (2012). Genealogía de las Herencias Coloniales. Entrevista a Santiago Castro-Gómez. En Andamios Volumen 9, número 20, septiembre-diciembre, 2012, pp. 187-199.

LefF, E. (1998). Saber ambiental. Sustentabilidad, racionalidad, complejidad y poder. México; siglo XXI editores.

Mota, L., Sandoval, E. (2016). La falacia del desarrollo sustentable, un análisis desde la teoría decolonial. Iberoamérica Social: revista-red de estudios sociales, VI, pp. 89-104. Recuperado en http://iberoamericasocial.com/ la-falacia-deldesarrollo-sustentable-analisis-desdela-teoria-decolonial

Organización de las Naciones Unidas (1987). Informe de la Comisión Mundial sobre Medio Ambiente y Desarrollo. Cuadragésimo segundo periodo de sesiones.

Pretty, J. et al. (2007). Introduction to Environment and Society. The Sage handbook of environment and society. Londo; SAGE. Recuperado en: https://www.researchgate. net/publication/239922862_Introduction_to_Environment_and_Society/ link/00b7d5289fc438ca7b000000/download

Shiva, V. (1996) Recursos. En Diccionario del desarrollo. Una guía del conocimiento como poder. Perú, Editor Sachs Pratec.

Toledo, V. (2019) ¿Qué es el capitaloceno? En La Jornada 9 de abril de 2019. Recuperado en https://www.jornada.com.mx/2019/04/09/opinion/017a2pol?fbclid=IwAR2ce7jqjVsb Ou-HcGOJXB2kvUlUYeNPpVHuf6YLhW1O4lvlaVIsVaN-a5U\#

Toledo, V. (2015) ¿De qué hablamos cuando hablamos de sustentabilidad? Una propuesta ecológico-política. En Interdisciplina 3, no 7 (2015): 35-55.

Toledo, V. y Ortiz, B. (2014) México, regiones que caminan hacia la sustentabilidad. Una geopolítica de las resistencias bioculturales. Puebla, México; Universidad Iberoamericana Puebla.

Zaremberg, G. y Guarneros, V. (2019) Conversando con Goliat: Participación, movilización y represión en torno a conflictos neoextractivistas y ambientales. FLACSO México-De Montfort University. 